\title{
Functions for aboveground biomass estimation derived from satellite images data in Mediterranean agroforestry systems
}

\author{
Ana Cristina Gonçalves $\mathbb{D} \cdot$ Adélia M. O. Sousa $\cdot$ Paulo Mesquita
}

Received: 10 April 2017 / Accepted: 28 May 2018/Published online: 2 June 2018

(C) Springer Science+Business Media B.V., part of Springer Nature 2018

\begin{abstract}
Forest biomass has been having an increasing importance in the world economy and in the evaluation of the forests development and monitoring. The main goal of this study is the development of functions for the estimation of aboveground biomass, using crown cover as independent variable, for Quercus rotundifolia, Quercus suber and Pinus pinea in agroforestry systems, both for monospecies and multispecies stands, based on Portuguese data. Crown cover per specie was derived from crown horizontal projection obtained by processing very high
\end{abstract}

A. C. Gonçalves ( ()

Departamento de Engenharia Rural, Escola de Ciências e Tecnologia, Instituto de Ciências Agrárias e Ambientais Mediterrânicas (ICAAM), Instituto de Investigação e Formação Avançada, Universidade de Évora, Apartado 94, 7002-544 Évora, Portugal

e-mail: acag@uevora.pt

\author{
A. M. O. Sousa \\ Departamento de Engenharia Rural, Escola de Ciências e \\ Tecnologia, Instituto de Ciências Agrárias e Ambientais \\ Mediterrânicas (ICAAM), Centro de Inovação em \\ Tecnologias de Informação (CITI), Instituto de \\ Investigação e Formação Avançada, Universidade de \\ Évora, Apartado 94, 7002-554 Évora, Portugal \\ e-mail: asousa@uevora.pt \\ P. Mesquita \\ Departamento de Engenharia Rural, Escola de Ciências e \\ Tecnologia, Universidade de Évora, Apartado 94, \\ 7002-554 Évora, Portugal \\ e-mail: pmesquita@uevora.pt
}

spatial resolution satellite images (Quickbird and Worldview-2), with contrast split segmentation method and object-oriented classification. The stand species composition distinguished species and monospecies from multispecies stands. The best model was the one with crown cover and dummy variables for composition as explanatory variables, reflecting the differences between species and stand structure. Aboveground biomass with this function should ideally be calculated with the grid areas applied in this study, though similar accuracies can be obtained for other grid sizes.

Keywords Quickbird · Worldview-2 - Regression · Dummy variables · Grid area size

\section{Introduction}

Agroforestry systems are recognised for their importance in biomass production, both carbon sequestration (in vegetation and soil) and as a source of biomass for energy (Jose and Bardhan 2012). These systems enhance the production perpetuity and sustainability (Nerlich et al. 2013; Eichhorn et al. 2006; Jose et al. 2004). In Europe holm oak (Quercus rotundifolia Lam.) and umbrella pine (Pinus pinea L.) were identified as target species for agroforestry systems (Reisner et al. 2007). In addition, these systems have 